\title{
A Research Methodology Curriculum for Undergraduate Students in Nuclear Medicine Technology
}

\author{
Cybil J. Nielsen
}

School of Medicine, Indiana University, Indianapolis, Indiana

\begin{abstract}
The purpose of this article is to introduce nuclear medicine technology (NMT) educators to a way of incorporating research methodologies into the curriculum. Methods: Research methodology is taught in the NMT program at Indiana University in 5 courses, 1 for each semester of the 5-semester program (introduction to research articles and statistics, design of a mock group project and an individual project, collection of data, writing of the research paper, and presentation of the abstract and mentoring). These steps could be combined for programs that are shorter or have credit hour restrictions. Results: In the past $4 \mathrm{y}$, all Indiana University NMT students presented their research abstracts as part of a continuing education program for technologists. Seventeen of 25 (68\%) presented their abstracts at a regional professional meeting, and 6 of $25(24 \%)$ presented their abstracts at a national professional meeting. Three of those $6(50 \%)$ received travel grants. Two students submitted their research for publication, and one was accepted. Conclusion: The goal of incorporating a research methodology program into the nuclear medicine program should be to introduce undergraduates to the research process and instill excitement about continuing to participate in research throughout their career.
\end{abstract}

Key Words: undergraduate; research; methodology

J Nucl Med Technol 2018; 46:70-74

DOI: $10.2967 /$ jnmt.117.202648

$\mathbf{U}$ ndergraduate students benefit from research experiences (1), and research methodology has become an important part of the nuclear medicine technology (NMT) curriculum (2). There are many ways to incorporate research methods into an NMT program. This article is based on the research program I implemented in the NMT program at Indiana University. My research program is part of a $2+2$ program, meaning that students participate in $2 \mathrm{y}$ of prerequisite work before entering the approximately $2-y$ NMT program. Students actually complete a full 5 semesters in the NMT program, beginning in the summer semester before their junior year.

Received Oct. 4, 2017; revision accepted Dec. 6, 2017.

For correspondence or reprints contact: Cybil J. Nielsen, Indiana University, 1120 W. Michigan St., CL-120, Indianapolis, IN 46202.

E-mail: cybniels@iupui.edu

Published online Dec. 22, 2017.

COPYRIGHT (c) 2018 by the Society of Nuclear Medicine and Molecular Imaging.
The purpose of the program is to introduce students to the importance of performing research, the types of research methodologies, and the need to be a critical reader of journal articles. This introduction to research provides the groundwork they need as they move through their careers as nuclear medicine technologists. It is important to emphasize that producing results that will change the practice of NMT is not the purpose of this program. The outcomes and learning objectives are listed in Table 1 and are adapted from the Nuclear Medicine Technology Competency Based Curriculum Guide, fifth edition, of the Society of Nuclear Medicine and Molecular Imaging (SNMMI) (2).

My program covers five 1-credit-hour courses, 1 for each semester of the 5-semester NMT program (introduction to research articles and statistics, design of a mock group project and an individual project, collection of data, writing of the research paper, and presentation of the abstract and mentoring). Several of these courses could easily be combined or abbreviated to accommodate programs that are shorter or have credit hour restrictions.

\section{MATERIALS AND METHODS}

\section{Introduction to Research Articles and Statistics}

The first-semester course focuses on introducing students to the library. Many colleges and universities allow students to access the library online. This is convenient for students, and they will take advantage of it. However, I find that students do not understand the difference between what can be found in a random online search (e.g., via Google) and what can be found in an online search of a school's library (3). The best way to help them understand is to take them to the library. I arrange with our librarian to give a presentation on library services and how to use them.

As part of the library orientation, my students are introduced to using citation software. The days of my counting the spaces, commas, and periods of a citation are over. EndNote (Clarivate Analytics) is a popular type of citation software used to manage information (4). I require my students to download the software to their personal electronic devices in the beginning of the program and use it throughout, to prepare them if they wish to pursue publication either as a student or later as a technologist. The Journal of Nuclear Medicine Technology (JNMT) has its own output style for EndNote that can be downloaded from the EndNote site.

During this first semester, I introduce students to the difference between a research article and a literature review article, assigning them one of each to read and giving them a series of questions that encourage them to compare the two types. I keep in mind that this is the beginning of the program and that students will not 
Outcome

Use information provided by comparative effectiveness research/evidence-based medicine

Demonstrate basic concepts of research methods

Demonstrate effective oral and written communication skills
Learning objective

\section{Analyze literature to determine applicability to profession}

Demonstrate working knowledge of regulatory compliance associated with research studies

Protect and preserve personal and confidential patient information Comply with current federal, state, and institutional regulations Apply problem solving and critical thinking skills through research activities

Apply values and ethical principles in relation to research activities Demonstrate technical writing skills

Orally present professional information understand much of the content of the assigned articles. Therefore, I assign articles that are short, are relatively easy to read, and contain clinical subject matter that will be covered early. An example of a research article (5) and an example of a review article (6) are presented in the reference list.

Once students understand the difference, they learn about the sections of a research article and how to critically read one (7). They are given a series of questions to answer about a particular article, breaking it down to its components and identifying any limitations to the research that the article may not mention. I believe the only way to become a critical reader of journal articles is through practice. I assign journal article critiques throughout the program to help students build this skill.

In this introductory course, students also will need to become prepared for projects with human subjects. I have all students complete an online module on human-subject research that is available through the Collaborative Institutional Training Initiative (the CITI Program).

Finally, students will need a basic understanding of statistics in order to grasp the content of journal articles and perform their own research. I try not to teach the subject in too much depth, believing that the appropriate level at this stage is a brief overview of descriptive versus inferential statistics, $t$ tests (1-sample or 2-sample, paired or unpaired), ANOVA, and linear regression (8). I find that it is necessary to cover only how to choose an appropriate statistical method, how to perform it, and how to interpret its results. There is software (e.g., the Analysis Toolpak in Excel [Microsoft]) that can do all the calculations. If a student chooses a project that requires higher-order statistics, I recommend outside help such as the walk-in statistics clinic offered once a week by our university for this very purpose.

To summarize, the student is introduced to library and citation software, compares a research article with a review article, learns about the components of a research article and how to critique one, is introduced to research on human subjects (the CITI Program), and is introduced to statistics.

\section{Design of a Mock Group Project and an Individual Project}

The focus of the second-semester course is the design of research projects, beginning with a mock group project and then moving on to an individual project.

For the mock group project, I divide the students into 2 groups, assign a claim to each group, and guide them through the steps of creating a project to research the claim. For example, one claim could be that syringe shield A blocks $90 \%$ of the photons from a ${ }^{99 \mathrm{~m}} \mathrm{Tc}$ source; another could be that more photons from a ${ }^{99 \mathrm{~m}} \mathrm{Tc}$ source are blocked by syringe shield A than by syringe shield B. The claims I provide are simplistic, because the purpose of this exercise is only to introduce students to the steps of performing research.

I first have the students prepare an annotated bibliography that includes articles relating to the claim and answering the question of why it is important to research this claim. Students tend to have trouble with this part of the assignment. They want to be specific and find an article that directly explains what they are researching instead of an article that supports what they are researching. They are then required to write 2 paragraphs for each article they find, with the first paragraph summarizing the article and the second paragraph explaining how it supports their research.

I have found that students tend to want to jump immediately into research design, mainly the methodology and materials needed. At this point, I require my students to take a step back and define the research question, state the null and alternate hypotheses, and guess what they think the results might be. I then encourage students to think about multiple ways to design their research methodology, and I always find it interesting that given the same claim, my students will find different ways to design their data collection and measurements. For example, in the given project of evaluating syringe shields, they may use varying activities or varying volumes. They may use varying distances as well. They also need to decide on the equipment they will use (Geiger-Mueller meter, dose calibrator, portable ionization chamber, scintillation detector).

My students must also create a data collection sheet. I have them look at the statistical methodology when constructing their sheet. Often, their methodology will change as a result. The students then insert mock data and run their statistical method to see if it makes sense. This is a good way for them to check their work. I teach them that, to limit any bias, they should always complete their research design before collecting their data, and I have found that the best way for them to complete their design is to use mock data before collecting any real data.

I give my students the opportunity to collect their own data for this group mock project using a dedicated lab. If this lab is unavailable, use of the hot lab of a clinical site may be an option. I supervise my students but allow them to make mistakes during this data collection exercise. 
The final step of this group mock project is for my students to write an extended abstract or a brief paper that applies everything they have learned about research articles and uses the JNMT output format in EndNote. Educators should not become discouraged if the final product is less than ideal, as this is the students' first try at doing something like this. I consider this step an opportunity for them to practice writing before they do their individual research project. I also have them present their abstract to their classmates.

While the students are working through this group mock project, I encourage them to start brainstorming ideas in class for the individual project. For example, when they are working on their mock research question and hypotheses, I ask them to share with the class what their individual projects might be. For these individual projects, the students will need to make a claim or observation and then construct a research question. For example, the claim could be that heparin does not need to be used during red blood cell tagging, or the question could be whether estimated glomerular filtration rate affects SUVs.

I require my students to identify a research supervisor to help guide them through their project-someone who knows about what the student is researching and can fill in any knowledge gaps. For example, if the project involves infection control I suggest that they ask a nurse to be their supervisor, and if it involves radiation protection I suggest a physicist. I advise them to avoid choosing a recent NMT graduate, as new graduates tend to be busy starting their careers and not able to become an actively involved supervisor. I have students and their supervisors sign an agreement outlining the responsibilities of each in the project (Fig. 1). However, my students are ultimately responsible for all aspects of the project; the supervisor only guides them, holds them accountable for their progress, and answers questions.

To support their research claim, my students must create an annotated bibliography that includes 4 peer-reviewed journal articles compiled in the same format as for the mock group project.

When ready to define the materials and methods for their projects, the students must consider several factors. Is there a financial cost to the project? Does it include human subjects and require approval by an institutional review board? Can data be collected in the period allowed? Often, my students will change their project idea several times during this exercise. After my students have their research claim, I also invite a nuclear medicine physician to listen to their ideas and provide feedback on how to improve the design of their project.

At the end of this course, students prepare their data collection sheet and determine the statistical method they will use. If they require institutional review board approval, I encourage them to start this process as early as possible.

To summarize, students complete a group mock project in which they are assigned a claim, define the research question and hypotheses, review the literature, construct materials and methods, create a data collection sheet, run a mock-data statistical analysis, collect data, write an abstract or brief paper, and present it. Students then complete an individual project in which they state a claim and a research question, review the literature, propose a null or alternate hypothesis, find a research supervisor, construct materials and methods, use a statistical tool to run a mock-data analysis, and apply for the approval of the institutional review board if needed.

\section{Collection of Data}

The focus of the third-semester course is mainly independent study. The students are responsible for collecting and analyzing data and presenting their results to the class by the end of the term. To be cleared to collect data, students must meet with me to identify and discuss their research question, null and alternate hypotheses, and research design (e.g., materials and methods and statistical analysis techniques). At the time we meet, they must also submit a signed form from their research supervisor verifying the supervisor's involvement in the process. If a student is not cleared at this initial meeting, I allow them to meet with me one more time without consequence. If they are not cleared at the second meeting, their grade is dropped by one level. This is true for any subsequent meeting until they are cleared. I believe this incentive encourages students to plan early and take sole responsibility for timely completion of their research project.

From the very beginning, I encourage students to design a relatively uncomplicated project. After all, this is undergraduate research. The goal is for students to learn how to conduct quality research and receive an experience that motivates them to continue with research throughout their careers. I believe that the simpler and more straightforward this initial project is, the smoother their course of development will be. However, I find that many students still choose a project that is labor-intensive and time-consuming. As a result, this semester often proves difficult and stressful for them.

Once I clear students to collect their data, I have them continue conferring with me on their progress. A minimum of one month is allowed for data collection. The due date is at the end of the semester. At the beginning of the course I make it clear that the earlier they are cleared, the more time they will have to collect their data. Extensions are requested quite often and are allowed on a case-by-case basis.

At the end of the course, students submit their data collection sheet and statistical analysis. This is an important step because it allows me to provide final feedback before they write their paper. They then present their project as an abstract (introduction, hypotheses, materials and methods, results, conclusion, and discussion), but they are allowed more time (10-20 min) than is usual for an abstract presentation. It is interesting that at this point, many students want even more than the maximum allowed time to present their project.

To summarize, students first must be cleared to collect data, then collect their data, and finally present their project to the class.

\section{Writing of the Research Paper}

The focus of the fourth-semester course is writing the paper. I begin this course with a guest lecture by a medical writer. The writer explains the "hows" of writing a paper, such as writing the results (or even the conclusion) first, writing the abstract last, and not writing the introduction until just before writing the abstract.

I require my students to write their paper according to the rules presented in the JNMT Information for Authors. They submit their paper to me 3 times, and all 3 submissions are graded as final papers. The first submission is worth $60 \%$ of their grade; the second, 30\%; and the third, $10 \%$.

I encourage students to submit their papers as early as possible, and I grade them in the order in which I receive them. I inform students that it can take up to $2 \mathrm{wk}$ for me to grade their paper, because if all the papers were submitted on the due date, I would need 2 full weeks to finish grading them. 


\section{Research Supervisor Agreement}

Each student must have a research supervisor. The research supervisor can be:

- Technologist

- Nurse

- Physician

- Pharmacist

- Physicist

The research supervisor must sign an agreement with the student verifying their involvement in the project. The following are responsibilities of the research supervisor:

\section{The research supervisor:}

1. Should provide guidance on the nature of the research, including materials and methods and data collection and analysis.

2. Should be accessible to the student to meet regarding their progress

3. Should ensure the student is aware if their progress is inadequate or unacceptable

4. Should sign the following documents verifying they have been reviewed:

a. Research proposal/plan

b. Collected data

c. Statistical results of collected data

d. First paper

The student:

1. Should schedule appointments with the supervisor for guidance

2. Must provide the supervisor with the following at least one week before it is due:

a. Research proposal/plan

b. Collected data

c. Statistical results of collected data

d. First paper

2. Must write the paper independently

3. Is responsible for

a. Literature review

b. Data collection

c. Statistical analysis and forming a conclusion

Student Name Date

Student Signature

Research supervisor name Date Research supervisor signature

FIGURE 1. Research supervisor agreement.

I grade the first submission using tracked changes, providing many edits and comments. I tell my students that if their paper has few comments, either it is excellent (probably not the case) or it is written so poorly that I do not know where to start. This assures students, when their paper is returned with over 100 comments, that they are at least close to having a good paper. Students must 
all address all these comments before submitting the second paper, and I encourage them to meet with me if they need clarification on specific comments.

The second submission is graded by an external reviewer (the medical writer who spoke to the students in their first-semester course). Grading is based on what would be needed to submit the paper for publication. Occasionally, the recommendations by the external reviewer conflict with my comments on the first submission. When this happens, students are awarded extra points if I deducted points from the first submission.

The students then revise their paper and submit it a third time, and I award points if they addressed all the comments from the external reviewer. If I believe a paper is good enough to be submitted for publication, I privately inform the student and give permission to list me as an author. I tell all students that even if I have not recommended that they submit their article, they may still do so, but without listing me as an author.

To summarize, the instructor grades the first submission; an external reviewer, the second; and the instructor, the third, after which the paper is ready for publication.

\section{Presentation of the Abstract and Mentoring}

The final course in my research program allows fifth-semester students to present their abstracts and mentor new students. Mentoring of new students begins during the third-semester course, when new students are invited to attend the abstract presentations. Although these students may not understand the scope of the projects, they will have some insight on where they will be the following year. Mentoring continues during the fifthsemester course. As the senior students are preparing their abstracts for presentation, they work with students who are taking the second-semester course, helping with their research designs. I have found that this step helps students move from being mentored into the role of mentoring.

I provide students with 3 venues to present their research. First, they present their abstract to the nuclear medicine physician who assisted them with their research design during the second semester. This presentation is done in a workshop setting, where feedback is immediate.

The second presentation is to the clinical technologists. I obtain VOICE approval (Verification of Involvement in Continuing Education) for the student abstract presentations and invite all the technologists from their clinical sites to attend. Many of the technologists have heard from the students about their projects, and this is a way for them to see the final product.

The third presentation is at the annual meeting of the Central Chapter of the SNMMI. If students do not wish to travel to the chapter meeting, I require them to present their research in the form of a poster on Research Day at our university.

To summarize, senior students mentor new students on their research designs, and they present their abstract to the nuclear medicine physician, to local technologists, and at a chapter meeting or on Research Day.

\section{RESULTS}

This program has been in use at Indiana University for $4 \mathrm{y}$ and has been completed by 25 students, all of whom presented their research abstracts as part of a continuing education program for technologists. Seventeen of 25 (68\%) presented their abstracts at the annual meeting of the Central Chapter of the SNMMI. Six of $25(24 \%)$ presented their abstracts at the annual meeting of the SNMMI. Three of those $6(50 \%)$ received travel grants. Two students submitted their research for publication in JNMT, and one was successful.

\section{DISCUSSION}

The research program at IU has been one of the most rewarding aspects of my career as an NMT educator. It is illuminating to walk students through the research process in a multisemester approach. By breaking it down into manageable pieces, students are able to develop competence in research practices. This research program allows students many educational experiences: mentoring new students, public speaking, networking at professional meetings, etc. In addition, my students add their research projects to their resumes, which provides them with a conversation tool during an interview. Finally, my students also report a high degree of satisfaction regarding this research program at the conclusion of the program during exit interviews.

\section{CONCLUSION}

Nuclear medicine technology educators searching for a way to incorporate research methodologies into their curriculum should allow for creativity. Different programs will use different ways to add research methodologies to the curriculum. The ultimate goal of any research methodology program should be to introduce undergraduates to the research process and instill excitement about continuing to participate in research throughout their career.

\section{DISCLOSURE}

No potential conflict of interest relevant to this article was reported.

\section{REFERENCES}

1. Russell SH, Hancock MP, McCullough J. Benefits of undergraduate research experiences. Science. 2007;316:548-549.

2. Nuclear medicine technology competency-based curriculum guide. 5 th ed. Society of Nuclear Medicine and Molecular Imaging website. http://snmmi.files.cms-plus. com/FileDownloads/Education/SNMMI\%20Nuclear\%20Medicine\%20Technology\% 20Competency $\% 20$ Based $\% 20$ Curriculum $\% 20$ Guide $\% 20-\% 205$ th $\% 20$ Edition $\%$ 20docx\%20v2.pdf. Accessed January 3, 2018.

3. Georgas H. Google vs. the library (part II): student search patterns and behaviors when using Google and a federated search tool. portal: Libraries and the Academy. 2014;24:503-532.

4. Butros A, Taylor S. Managing information: evaluating and selecting citation management software, a look at EndNote, RefWorks, Mendeley and Zotero. ResearchGate website. https://www.researchgate.net/publication/268428881_ Managing_information_evaluating_and_selecting_citation_management_software_ a_look_at_EndNote_RefWorks_Mendeley_and_Zotero. Published January 2011. Accessed January 3, 2018.

5. Pigmon SR, Weatherman KD, Brehl NC, Nielsen CJ. The necessity of using heparin in the UltraTag RBC kit when tagging blood for a nuclear medicine study. J Nucl Med Technol. 2016;44:230-233.

6. Pagnanelli RA, Basso DA. Myocardial perfusion imaging with ${ }^{201}$ Tl. J Nucl Med Technol. 2010;38:1-3.

7. Greenhalgh T. How to Read a Paper: The Basics of Evidence-Based Medicine. Hoboken, NJ: John Wiley and Sons; 2014.

8. Petrie A, Sabin C. Medical Statistics at a Glance. Hoboken, NJ: John Wiley and Sons; 2013. 